\title{
Expression Profile of LGR5 and Its Prognostic Significance in Colorectal Cancer Progression
}

Bo Gun Jang, ${ }^{*}$ Hye Sung Kim, ${ }^{*}$ Weon Young Chang, ${ }^{\dagger}$ Jeong Mo Bae, ${ }^{\ddagger \S}$ Woo Ho Kim, ${ }^{\ddagger}$ and Gyeong Hoon Kang

From the Departments of Pathology* and General Surgery, ${ }^{\dagger}$ Jeju National University School of Medicine, Jeju; and the Department of Pathology ${ }^{\ddagger}$ and the Laboratory of Epigenetics, ${ }^{\S}$ Cancer Research Institute, Seoul National University College of Medicine, Seoul, Republic of Korea

Accepted for publication

June 19, 2018.

Address correspondence to Gyeong Hoon Kang, M.D., Ph.D., Department of Pathology, Seoul National University College of Medicine, 103 Daehak-ro, Jongno-gu, Seoul 110-799, Republic of Korea. E-mail: ghkang@snu. ac.kr.

\begin{abstract}
We investigated the expression profile of leucine-rich, repeat-containing, G-protein-coupled receptor 5 (LGR5) during colorectal cancer (CRC) progression and determined the prognostic impact of LGR5 in a large cohort of CRC samples. LGR5 expression was higher in CRCs than in normal mucosa, and was not associated with other cancer stem cell markers. LGR5 positivity was observed in $68 \%$ of 788 CRCs and was positively correlated with older age, moderately to well-differentiated cells, and nuclear $\beta$-catenin expression. Enhanced LGR5 expression remained persistent during the adenoma-carcinoma transition, but markedly declined in the budding cancer cells at the invasive fronts, which was not due to altered wingless-type mouse mammary tumor virus integration site family (Wnt) or epithelial-mesenchymal transition signaling. LGR5 showed negative correlations with microsatellite instability and CpG island methylator phenotype, and was not associated with KRAS or BRAF mutation. Notably, LGR5 positivity was an independent prognostic marker for better clinical outcomes in CRC patients. LGR5 overexpression attenuated tumor growth by decreasing ERK phosphorylation along with decreased colony formation and migration abilities in DLD1 cells. Likewise, knockdown of LGR5 expression resulted in a decline in the colony-forming and migration capacities in LoVo cells. Taken together, our data suggest a suppressive role of LGR5 in CRC progression. (Am J Pathol 2018, 188: 2236-2250; https://doi.org/ 10.1016/j.ajpath.2018.06.012)
\end{abstract}

Leucine-rich, repeat-containing, G-protein-coupled receptor 5 (LGR5), a wingless-type mouse mammary tumor virus integration site family (Wnt) target gene that functions as a receptor for Wnt agonist R-spondins (RSPOs), is an adult stem cell marker in the intestines, hair follicles, liver, and ovary, as revealed by in vivo lineage tracing. ${ }^{1-6}$ Deletion of $A p c$ in mice in $\mathrm{Lgr}^{+}$cells or in more differentiated cells showed that mainly $\operatorname{Lgr}^{+}$stem cell fraction can form gradually proliferating adenomas on abnormal Wnt pathway activation, suggesting that $\operatorname{Lgr}^{+}$cells are the cells of origin of intestinal tumors. ${ }^{7}$ In addition, in vivo lineage tracing demonstrated the stem cell activity of $\operatorname{Lr} 5^{+}$cells in mouse intestinal adenomas produced by the deletion of $A p c$ in $\operatorname{Lgr5}^{+}$stem cells. $^{8}$

LGR5 is reportedly overexpressed in human colorectal adenomas and cancers, ${ }^{9-13}$ as well as in other solid tumors such as hepatocellular carcinoma, basal cell carcinoma, and neuroblastoma. ${ }^{14-16}$ A subpopulation of $L G R 5^{+}$cells were found to be a clonogenic fraction in vitro and tumorigenic population in vivo from both colorectal cancer (CRC) cell lines and primary colorectal tumors. ${ }^{17}$ More recently, it was demonstrated that selective $L G R 5^{+}$cell ablation resulted in the inhibition of primary tumor growth or regression of tumors, ${ }^{18,19}$ and that $L G R 5^{+}$cells were important in the formation and maintenance of liver metastasis of CRCs. ${ }^{19}$ These results suggest that $L G R 5^{+}$colon cancer cells serve as cancer stem cells (CSCs) in growing cancer tissues; this knowledge can offer a therapeutic opportunity to manage primary and metastatic CRCs.

In many studies, the expression of LGR5 has been associated with poor prognosis in $\mathrm{CRC},{ }^{20-24}$ and some

\footnotetext{
Supported by National Research Foundation of Korea (NRF) Basic Science Research Program, Ministry of Science, ICT \& Future Planning grants NRF-2017R1C1B5017468 (B.G.J.) and NRF-2017R1C1B1004912 (H.S.K.); and the Korea government NRF grant 2011-0030049 (G.H.K.).

B.G.J. and H.S.K. contributed equally to this work.

Disclosures: None declared.
} 
meta-analyses have concluded that LGR5 is an undesirable prognostic factor in CRC patients. ${ }^{25-27}$ However, these studies used immunohistochemistry analysis to evaluate the expression of LGR5 and it is well known that there is no antibody that specifically marks $L G R 5^{+}$cells at the intestinal stem cell niche, thus casting great doubt on the reliability of these results. In contrast, RNA in situ hybridization (ISH) clearly demonstrated $L G R 5$-expressing cells at the crypt bases and has been recognized as the most reliable method for detecting $L G R 5$ on formalin-fixed, paraffin-embedded (FFPE) tissues obtained from CRC patients. ${ }^{11,13,28}$ Ziskin

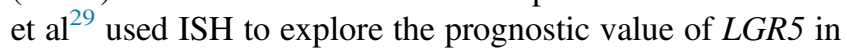
a large-scale series of CRCs and showed that $L G R 5$ was not associated with poor clinical outcomes. Therefore, the prognostic significance of LGR5 remains controversial, and studies with a large number of CRC samples using an RNA ISH are necessary.

In this study, we examined the expression of $L G R 5$ in a large cohort of human CRC samples using RNA ISH and assessed its prognostic significance. Furthermore, we analyzed changes in the expression of $L G R 5$ during CRC progression: adenoma-carcinoma transition, tumor budding, and lymph node metastasis. The functional implications of LGR5 in cancer growth and migration were also explored in CRC cell lines.

\section{Materials and Methods}

\section{Subjects}

CRC samples were collected from 1133 patients who underwent surgical resection at Seoul National University Hospital (Seoul, Republic of Korea) between 2004 and 2008. In total, 785 patients were treated with one of the following systemic chemotherapy regimens: FL (5-fluorouracil and leucovorin), FOLFOX (oxaliplatin, leucovorin, and 5-fluorouracil), XELOX (oxaliplatin and capecitabine), FOLFIRI (irinotecan, leucovorin, and 5-fluorouracil), capecitabine (Xeloda), and others. Among them, 109 patients also received radiation therapy. Clinicopathologic data, including patient age, sex, tumor size, location, histologic type, evidence of lymphovascular invasion, cancer stage as defined by the American Joint Committee on Cancer/Union Internationale Contre le Cancer, seventh edition, ${ }^{30}$ time of death, tumor recurrence, and follow-up time were obtained by reviewing the clinical and pathologic reports. Tumor differentiation was determined using a three-tier grading system as described in the World Health Organization's Classification of Tumours of the Digestive System. ${ }^{31}$ Tumor budding was defined as a single tumor cell or a group of less than five tumor cells at the invasive fronts. A total of 206 CRC samples were obtained from the patients at Jeju National University Hospital (Jeju, Republic of Korea); 24 cases were CRCs arising from adenomas, and 182 cases were conventional CRCs, the clinicopathologic characteristics of which are shown in
Supplemental Tables S1 and S2, respectively. The histopathologic features of the CRCs were evaluated by two gastrointestinal pathologists (J.M.B. and G.H.K.). In addition, 32 paired, fresh-frozen CRC tissue samples and matched normal tissue samples were provided by the Jeju National University Hospital Biobank, a member of the National Biobank of Korea, for which informed consent was obtained from all subjects. All procedures were performed in accordance with the Declaration of Helsinki of 1964 and later versions, and the study protocol was approved by the institutional review boards of Seoul National University Hospital and Jeju National University Hospital.

\section{DNA Extraction}

FFPE tissue samples of 1133 primary CRCs were retrieved from pathology archives. Genomic DNA isolation from all FFPE tissues was performed as follows: tumor spots (tumor cells $>70 \%$ of the selected area) were microdissected using a surgical blade from $10 \mu \mathrm{m}$-thick, unstained tissues. Dissected tumor tissues were incubated for digestion in lysis buffer $[100 \mathrm{mmol} / \mathrm{L}$ Tris- $\mathrm{HCl}(\mathrm{pH} 8.0), 10 \mathrm{mmol} / \mathrm{L}$ EDTA (pH 8.0), $1 \mathrm{mg} / \mathrm{mL}$ proteinase $\mathrm{K}$, and $0.05 \mathrm{mg} / \mathrm{mL}$ tRNA] at $55^{\circ} \mathrm{C}$ for 2 days, followed by a $95^{\circ} \mathrm{C}$ incubation for 10 minutes to inactivate proteinase $\mathrm{K}$. The extracted DNA was stored at $-20^{\circ} \mathrm{C}$ until used for molecular studies including analyses for KRAS/BRAF mutations, microsatellite instability (MSI), and $\mathrm{CpG}$ island methylation phenotype (CIMP).

\section{MSI Analysis}

All of 1133 CRCs were subjected to MSI analysis using fluorescent multiplex PCR methods with five National Cancer Institute-recommended microsatellite markers (BAT25, BAT26, D5S346, D17S250, and D2S123). ${ }^{32}$ The MSI status of each CRC case was classified as one of three types: MSI-high indicates two or more unstable markers among the five markers; MSI-low indicates one unstable marker among the five markers; and MSI-stable indicates no unstable marker among the five markers.

\section{DNA Methylation Analysis}

DNA analysis for the determination of CIMP status was performed as previously described. ${ }^{33}$ Sodium bisulfite modification of genomic DNA samples was conducted in all 1133 CRC tissues. The quantitative measurement of the promoter $\mathrm{CpG}$ island methylation of eight CIMP marker genes [MLH1, NEUROG1, CRABP1, CACNA1G, CDKN2A (p16), IGF2, SOCS1, and RUNX3] was conducted using the methylation-specific real-time PCR method (MethyLight assay; Qiagen, Valencia, CA). A CIMP-high tumor was defined as having five or more hypermethylated markers; a CIMP-low tumor, as having one to four hypermethylated markers; and a CIMP-negative tumor, as having no 
hypermethylated markers. A hypermethylated $\mathrm{CpG}$ island locus was identified as having a percentage of methylated reference value of $>4$. The MethyLight analysis of each CIMP marker gene was repeated three times independently, and when two or more of the three experiments showed a percentage of the methylated reference value of $>4$, the final determination of the promoter hypermethylation was made.

\section{KRAS/BRAF Mutation Analysis}

$K R A S / B R A F$ mutation analysis was performed as previously described. ${ }^{33}$ Mutations in KRAS codons 12 and 13 and $B R A F$ codon 600 were detected using PCR-restriction fragment length polymorphism and direct-sequencing techniques. Among the $788 \mathrm{CRCs}, 39$ and 81 samples were excluded from the $K R A S$ and $B R A F$ mutation analyses, respectively, due to insufficient DNA amounts.

\section{Tissue Microarray Construction}

Twenty tissue microarrays containing 1133 CRCs from Seoul National University Hospital were generated as previously described. ${ }^{33}$ Briefly, through a histologic examination, representative tumor portions including $>70 \%$ of the cell population were marked in each case. In CRCs from Seoul National University Hospital, core-tissue biopsy samples (2 $\mathrm{mm}$ in diameter) were obtained from each FFPE CRC (donor blocks) and arranged in a new recipient paraffin block (tissue array block) using a trephine apparatus (SuperBioChips Laboratories, Seoul, Republic of Korea). In CRCs from Jeju National University Hospital, two tissue microarrays containing 24 pairs of adenoma and carcinoma portions and 15 tissue microarrays containing 182 cases of CRCs were constructed with cores $4 \mathrm{~mm}$ in diameter. For ulcerofungating cancers, both superficial and invasive areas were included, and, if present, metastatic cancers of the lymph node were also included.

\section{Immunohistochemistry Analysis}

Immunohistochemistry analysis was performed on $4-\mu \mathrm{m}$ tissue microarray sections using a Ventana BenchMark XT Staining system (Leica Microsystems, Wetzlar, Germany) according to the manufacturer's instructions. The primary antibodies used were anti- $\beta$-catenin (catalog number $17 \mathrm{C} 2$; Novocastra Laboratories, Newcastle, UK; 1:800), E-cadherin (catalog number 35; BD Biosciences, San Jose, CA, 1:800), and vimentin (catalog number V9; Thermo Fisher Scientific, Waltham, MA; 1:1500). Nuclear $\beta$-catenin staining was considered as positive when $>10 \%$ of the tumor cell nuclei were strongly stained for $\beta$-catenin.

\section{RNA in Situ Hybridization and Interpretation}

RNA ISH was performed using the RNAScope FFPE assay kit (Advanced Cell Diagnostics, Hayward, CA) as previously described. ${ }^{28}$ Briefly, 4- $\mu \mathrm{m}$ FFPE tissue sections were pretreated with heat and protease digestion followed by hybridization with the probe. Then, a horseradish peroxidase-based signal-amplification system was hybridized to a probe before color development with 3,3'-diaminobenzeidine tetrahydrochloride. The housekeeping gene ubiquitin $\mathrm{C}$ and the bacterial gene $D a p B$ served as a positive and negative control, respectively. CRCs with ubiquitin $\mathrm{C}$ easily visible under a $\times 10$ objective lens were considered to be adequate according to the manufacturer's recommendation. Finally, 788 CRCs were adequate for the analysis. Positive staining was indicated by brown punctate dots in the nucleus and/or cytoplasm. LGR5, SNAIL, SLUG, and ZEBI expression levels were quantified according to the manufacturer's scoring guideline: 0 indicates no staining or less than one dot per cell; 1 indicates 1 to 3 dots per cell (visible at original magnification $\times 20$ to $\times 40$ ); 2 indicates 4 to 10 dots per cell and no or very few dot clusters (visible at $\times 20$ to $\times 40$ ); 3 indicates $>10$ dots per cell and $<10 \%$ positive cells with dot clusters (visible at $\times 20$ ); and 4 indicates $>10$ dots per cell and $>10 \%$ positive cells with dot clusters (visible at $\times 20$ ). Scoring was done by two pathologists (B.G.J. and G.H.K.) independently. In the case of conflicting results, the case was reviewed and discussed until a consensus was reached. LGR5 status was considered as positive if the ISH score was $>2$.

\section{RNA Extraction and Real-Time Quantitative PCR}

Total RNA was extracted from 32 paired fresh-frozen CRC samples and noncancerous colon tissue samples using TRIzol reagent (InvitroGen, Carlsbad, CA). RNA (1 to $2 \mu \mathrm{g}$ ) was subjected to reverse transcription with oligo-dT primers and the GoScript reverse-transcription system (Promega, Madison, WI). cDNA was subsequently used to perform real-time PCR with Premix EX Taq (Takara Bio, Shiga, Japan) following the manufacturer's instructions, and the cycling conditions were as follows: initial denaturation for 30 seconds at $95^{\circ} \mathrm{C}$, followed by 40 cycles of $95^{\circ} \mathrm{C}$ for 1 second and $60^{\circ} \mathrm{C}$ for 5 seconds in a StepOne Plus real-time PCR system (Applied Biosystems, Foster City, CA). The TaqMan gene expression assays were used as follows: Hs00173664_m1 (LGR5), Hs00270888_s1 (ASCL2), Hs00197437 (OLFM4), Hs00362096-m1 (EPHB2), Hs02379687_s1 (CD24), Hs01075684_m1 (CD44), Hs 01009250_m1 (PROM1/CD133), Hs00233455_m1 (ALCAM/ CD166), and Hs0275899_g1 (GAPDH). GAPDH served as the endogenous control.

\section{Colon Cancer Cell Lines}

Ten human CRC cell lines (DLD-1, HT29, SW620, HCT116, HCT15, LoVo, SW480, KM12C, KM12L4, and KM12SM) were purchased from the Korean Cell Line Bank (Seoul, Republic of Korea). Cells were cultured in RPMI1640, minimal essential medium, Dulbecco's modified Eagle's medium, or L15 medium (Welgene, Daegu, Republic of Korea) containing 10\% fetal bovine serum 
(Gibco, Carlsbad, CA) and 1\% penicillin/streptomycin (Gibco) and maintained at $37^{\circ} \mathrm{C}$ in a humidified incubator with $5 \% \mathrm{CO}_{2}$.

\section{Antibodies and Reagents}

Anti-LGR5 and anti- $\beta$-actin antibodies were purchased from Abcam and Sigma, respectively. Anti-vimentin antibodies, anti-mouse IgG-horseradish peroxidase, and anti-rabbit $\operatorname{IgG}$-horseradish peroxidase antibodies were purchased from Santa Cruz Biotechnology (Dallas, TX). The anti-SNAIL (zinc finger protein SNAI1), anti-SLUG (zinc finger protein SNAI2), anti-ZEB1 (zinc finger E-boxbinding homeobox 1), anti-E-cadherin, anti-claudin-1, anti-ERK, anti-AKT, anti- $\beta$-catenin, anti-phospho (p)-ERK, and anti-pAKT antibodies were purchased from Cell Signaling Technologies (Beverly, MA). Recombinant human RSPO2 and transforming growth factor (TGF)- $\beta_{1}$ were purchased from PeproTech (Rocky Hill, NJ).

\section{Western Blot Analysis}

Cellular proteins were extracted from colon cancer cells in lysis buffer (iNtRON Biotechnology, Seongnam, Republic of Korea) and protein levels were measured with the BCA Protein Assay Kit (Pierce, Rockford, IL). Cell lysates were separated on $10 \%$ SDS-polyacrylamide gel and transferred electrophoretically to PVDF Membrane (EMD Millipore Corporation, Bedford, MA). After transfer, PVDF membranes were blocked with $5 \%$ nonfat dry milk in Tris-buffered saline-Tween-20 for 1 hour. After extensive washes in $0.05 \%$ Tris-buffered saline-Tween-20, the membranes were incubated with a primary antibody. After overnight incubation at $4^{\circ} \mathrm{C}$ and washing with Tris-buffered saline-Tween-20, blots were incubated for 1 hour at room temperature with a secondary antibody. The target proteins were detected using the chemiluminescent reagents and visualized in the Alliance Mini HD9 chemiluminescence documentation system (Uvitec, Cambridge, UK).

\section{Transfection}

Full-length cDNA encoding LGR5 (pEX-LGR5) was purchased from GeneCopoeia (Rockville, MD) and cDNA encoding SNAIL (pCMV6-SNAIL), SLUG (pCMV6SLUG), and ZEB1 (pCMV6-ZEB1) were from OriGene (Rockville, MD). LGR5 siRNA pool was purchased from Dharmacon (Lafayette, CO). Cells were seeded at $1 \times 10^{6}$ cells/well in 6-well plate after transfection with $5 \mu \mathrm{g}$ of cDNA (or control vector) or LGR5 siRNA using the Neon transfection system (Thermo Fisher Scientific). One or two days after transfection, cells were subjected to real-time PCR, Western blot, and functional assays. All experiments were performed at least two to three times independently.

\section{Proliferation Assay and Colony-Formation Assay}

As a proliferation assay, 24 hours after transfection in 6-well plates, cells were harvested and seeded at $5 \times 10^{3}$ cells/well on 96-well plates and incubated at $37^{\circ} \mathrm{C}$. After the addition of $10 \mu \mathrm{L}$ of Cell Counting Kit-8 reagent (Dojindo, Kumamoto, Japan) into each well and incubation for 1 hour, absorbance was measured at $450 \mathrm{~nm}$ using a spectrophotometer (Tecan, Mannedorf, Switzerland). As a colonyformation assay, 5000 to 10,000 cells were counted using Luna-II (Logos Biosystems, Gyeonggi-do, Republic of Korea) and seeded in a 60-mm culture dish and incubated for 10 to 20 days until distinguishable colony sizes appeared. Colonies were fixed with $70 \%$ methanol solution and stained with a $0.01 \%$ to $0.1 \%$ crystal violet solution. All experiments were performed at least two to three times independently.

\section{Wound-Healing Assay and Migration Assay}

For a wound-healing assay, cells were cultured in a SPLScar Block (SPL Life Sciences, Seongnam, Republic of Korea) in a 6-well plate until they were confluent after transfection with the control vector or LGR5. The block was composed of $500 \mu \mathrm{m}$-thick walls to artificially generate cell-free gaps. After removal of the block from the plate, culture medium was added and cellular migration was photographed at 0 and 48 hours. For a migration assay, cells were starved in serumfree RPMI medium for 3 hours. After starvation, cells were harvested and resuspended by trypsin treatment. Twentyfour-well culture plates were divided into upper and lower wells by a transwell insert (pore size, $8 \mu \mathrm{m}$; BD Biosciences). The upper surface of the transwell was loaded with $2 \times 10^{5}$ cells in $300 \mu \mathrm{L}$ of serum-free RPMI medium, and the lower wells contained $500 \mu \mathrm{L}$ of RPMI with $10 \%$ fetal bovine serum. After 24 hours of incubation, nonmigrated cells were removed from the top of each insert with a cotton swab. Migrated cells on the bottom surface were fixed with methanol for 10 minutes and counted after staining with crystal violet for 1 hour. All experiments were performed at least two to three times independently.

\section{Statistical Analysis}

Statistical analyses were performed using SPSS statistical software version 18.0 (SPSS, Chicago, IL) and Prism software version 5.0 (GraphPad Software, San Diego, CA). The correlation between $L G R 5$ positivity and clinicopathologic parameters was tested using the Pearson $\chi^{2}$ test or the Fisher exact test. Between-group comparisons of the real-time PCR data were performed using the $t$-test. The correlations between LGR5 and CSC markers were evaluated by the Spearman correlation test. Survival curves were estimated using the Kaplan-Meier method, and the log rank test was used to compare groups. Using the Cox proportional hazards model, univariate and multivariate analyses were 
performed to identify independent prognostic factors. A $P$ value of $<0.05$ was considered statistically significant.

\section{Results}

\section{LGR5 Is Up-Regulated in Human CRCs}

To evaluate the expression of LGR5 and stem cell-related markers in CRCs, real-time PCR was performed on a series of 32 pairs of fresh-frozen human CRC samples and adjacent noncancerous colon tissues. On comparison of individual cases, LGR5 mRNA expression was higher in CRC samples than in noncancerous tissue in most samples $(75 \%, 24$ of 32 cases) (Figure 1A). The mean LGR5 level was significantly up-regulated in CRCs compared with that in matched colon tissues $(P<0.01)$ (Figure 1B). LGR5 protein levels were also higher in cancer tissues than in normal tissues in three of the four cases examined (Figure 1C). As CD133, CD24, CD44, and CD166 have also been suggested as CSC markers in human CRCs, the expression of these markers was measured to examine whether $L G R 5$ expression is associated with any other candidate CSC marker. However, none of them showed significant correlations with LGR5 expression (Figure 1D). Several genes, such as ASCL2, EPHB2, and OLFM4, were found to be enriched in the $L G R 5^{+}$stem cells in the normal crypts, and they are considered as stem cell signature genes in the intestine. However, no significant associations between LGR5 and these stem cell-related markers were detected (Figure 1E), suggesting that the close relationship between LGR5 and stem cell signature genes maintained in the normal stem cell niche are lost during cancer development.
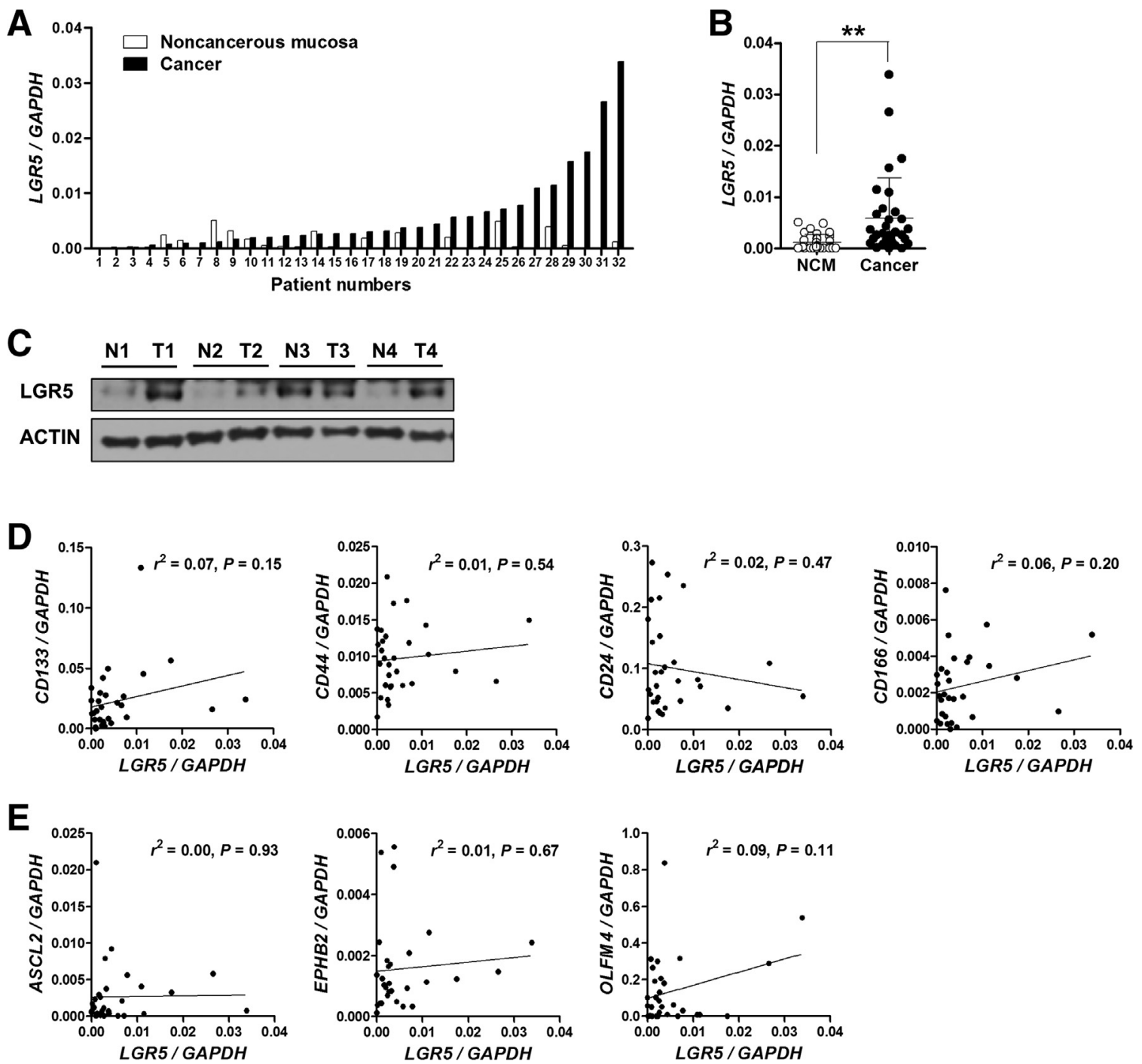

Figure 1 LGR5 expression in colorectal cancers (CRCS) and its correlation with cancer stem cell (CSC) and intestinal stem cell (ISC) markers. Real-time PCR analysis measured the expression of $\angle G R 5$ and CSC (CD133, CD44, CD24, and CD166) and ISC markers (ASCL2, EPHB2, and OLFM4) from 32 pairs of fresh-frozen CRCs and matched noncancerous mucosa (NCM). A and B: LGR5 mRNA expression is significantly higher in cancers than in NCM. C: Expression of LGR5 protein in CRCs and NCM samples was determined by immunoblot analysis. D and E: Scatterplots with regression lines showing the correlations between LGR5 and CSC or ISC markers expression. $n=4(\mathbf{C}) ; n=30(\mathbf{D}$ and $\mathbf{E}) .{ }^{*} P<0.01 . \mathrm{N}$, normal; $\mathrm{T}$, tumor. 
Clinicopathologic and Prognostic Significance of LGR5 Expression in CRCs

RNA ISH of normal colon tissues clearly shows a specific marking of $L G R 5^{+}$cells at the crypt base without nonspecific staining of the surrounding stromal cells or differentiated epithelial cells (Figure 2A), thus supporting the validity of the method. ISH for $L G R 5$ was performed on 20 tissue microarrays, and 788 cases were adequate for the analysis. ISH was scored on a scale of 0 to $4 ; 536$ cases (68\%) of CRCs were scored $>2$, defined as positive for LGR5 (Figure 2B). The clinicopathologic and molecular relevance of $L G R 5$ positivity is summarized in Tables 1 and 2. LGR5 expression was significantly higher in distal CRCs $(P=0.019)$, in CRCs with MSI-stable status $(P=0.011)$, and in CRCs that were CIMP-negative $(P=0.021)$. In addition, $L G R 5$ positivity exhibited a positive correlation with nuclear $\beta$-catenin expression, and

\section{A}

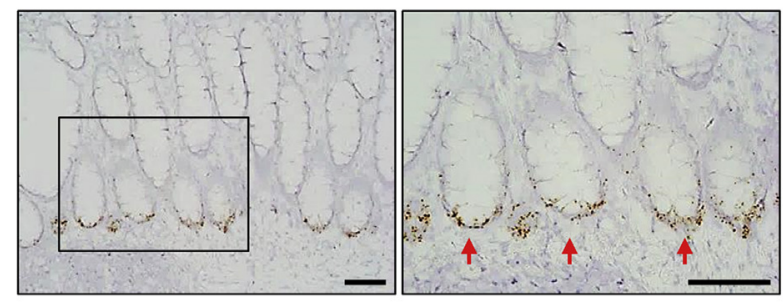

B
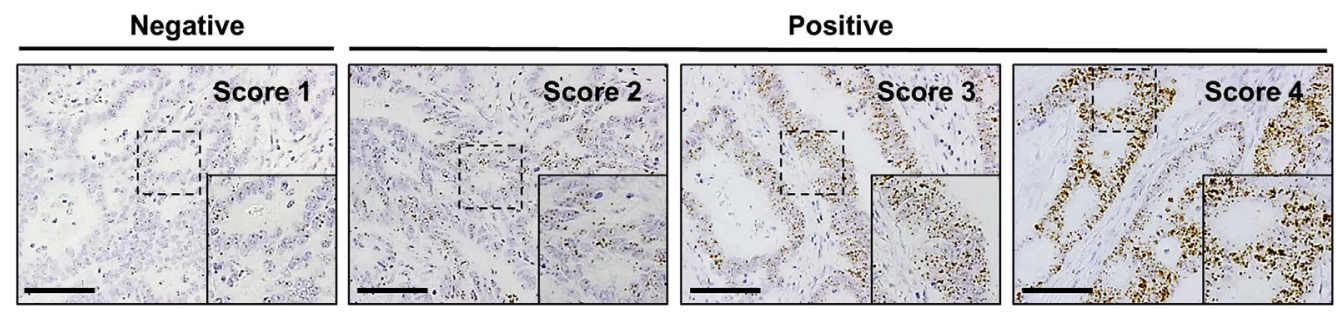

C

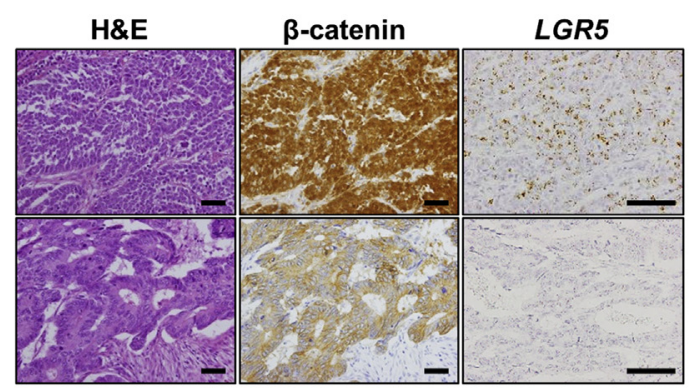

D
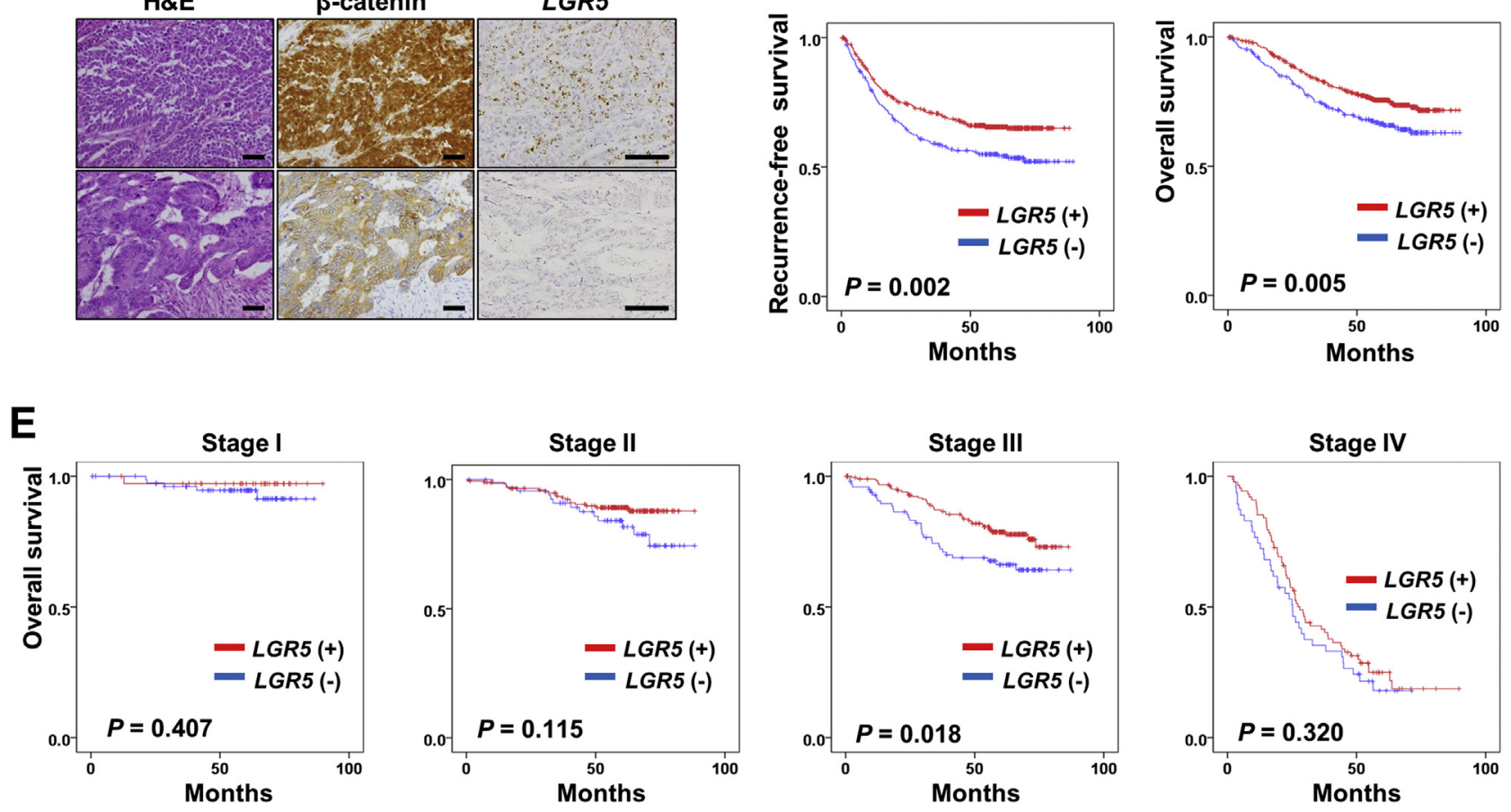

Figure 2 Overall and recurrence-free survival of colorectal cancer (CRC) patients with LGR5 expression. RNA in situ hybridization for LGR5 was performed in a large cohort of CRCs $(n=788)$. A: Boxed area in left panel of $\mathbf{A}$ is shown at a higher magnification in the right panel; $L G R 5^{+}$cells (arrows) are observed at the crypt bases of human colon tissues. B: LGR5 mRNA expression was classified into five scores: $0,1,2,3$, and 4 and colon cancers, with scores of 2, 3, or 4 considered to be positive. The insets show the boxed regions at higher magnification. C: Representative cases showing a positive correlation between nuclear $\beta$-catenin and LGR5 expression. D: Kaplan-Meier analysis demonstrates that LGR5 positivity shows better recurrence-free $(P=0.002)$ and overall $(P=0.005)$ survival rates. E: Prognostic significance of LGR5 expression is more apparent in stage III colon cancer patients. Scale bars $=50 \mu \mathrm{m}$. H\&E, hematoxylin and eosin. 
Table 1 Association between LGR5 Expression and the Clinicopathologic Characteristics

\begin{tabular}{|c|c|c|c|c|}
\hline \multirow[b]{2}{*}{ Characteristic } & \multirow[b]{2}{*}{ Total (\%) } & \multicolumn{2}{|l|}{ LGR5 } & \multirow[b]{2}{*}{$P$} \\
\hline & & $\begin{array}{l}\text { Negative } \\
(\%)\end{array}$ & $\begin{array}{l}\text { Positive } \\
(\%)\end{array}$ & \\
\hline Patients & $788(100)$ & $252(32)$ & $536(68)$ & \\
\hline \multicolumn{5}{|l|}{ Age } \\
\hline$\geq 60$ years & $458(58)$ & $145(32)$ & $313(68)$ & $0.877^{*}$ \\
\hline$<60$ years & $330(42)$ & $107(32)$ & $223(68)$ & \\
\hline \multicolumn{5}{|l|}{ Sex } \\
\hline Female & $315(41)$ & $106(34)$ & $209(66)$ & $0.436^{*}$ \\
\hline Male & $473(59)$ & $146(31)$ & $327(69)$ & \\
\hline \multicolumn{5}{|l|}{ Location } \\
\hline Proximal & $183(23)$ & $72(39)$ & $111(61)$ & $0.019 *$ \\
\hline Distal & $605(77)$ & $180(30)$ & $425(70)$ & \\
\hline \multicolumn{5}{|l|}{ Differentiation } \\
\hline WD & $35(4)$ & $8(23)$ & $27(77)$ & $0.117^{\dagger}$ \\
\hline MD & $728(92)$ & $232(32)$ & $496(68)$ & \\
\hline $\mathrm{PD}$ & $25(3)$ & $12(48)$ & $13(52)$ & \\
\hline \multicolumn{5}{|l|}{ Lymphatic invasion } \\
\hline Negative & $470(60)$ & $140(30)$ & $330(70)$ & $0.120^{*}$ \\
\hline Positive & $318(40)$ & $112(35)$ & $206(65)$ & \\
\hline \multicolumn{5}{|l|}{ Venous invasion } \\
\hline Negative & $687(87)$ & $217(32)$ & $470(68)$ & $0.568^{*}$ \\
\hline Positive & $101(13)$ & $35(35)$ & $66(65)$ & \\
\hline \multicolumn{5}{|l|}{ TNM-7 } \\
\hline I & $118(15)$ & $38(32)$ & $80(68)$ & $0.405^{\dagger}$ \\
\hline II & $247(31)$ & $69(28)$ & $178(72)$ & \\
\hline III & $288(37)$ & $98(34)$ & $190(66)$ & \\
\hline IV & $135(17)$ & $47(35)$ & $88(65)$ & \\
\hline \multicolumn{5}{|l|}{$\beta$-catenin } \\
\hline No nuclear stain & $267(34)$ & $112(42)$ & $155(58)$ & $<0.0001^{*}$ \\
\hline Nuclear stain & $514(66)$ & $139(27)$ & $375(73)$ & \\
\hline
\end{tabular}

*Fisher exact test.

†Pearson $\chi^{2}$ test.

MD, moderately differentiated; PD, poorly differentiated; TNM-7, Tumor Node Metastasis Staging System, Seventh Edition; WD, well differentiated.

a representative case is shown in Figure 2C. Conversely, $L G R 5$ had no correlations with sex, differentiation, lymphovascular invasion, mutation status of $B R A F$ or $K R A S$, or stage. Next, the prognostic impact of LGR5 was assessed in CRC patients using Kaplan-Meier analysis, which revealed that CRC patients with LGR5 positivity showed better clinical outcomes in both recurrence-free survival $(P=0.002)$ and overall survival $(P=0.005)$ (Figure 2D). The prognostic significance of LGR5 was more apparent in stage III CRC patients than in stage I, II, or IV CRC patients (Figure 2E). Remarkably, multivariate analysis demonstrated that LGR5 was an independent prognostic marker (hazard ratio $=0.712, P=0.017$ ) (Table 3).

\section{Altered Expression of LGR5 during CRC Progression}

Most CRCs develop through the adenoma-carcinoma sequence, and it has been demonstrated that LGR5 is
Table 2 Association between LGR5 Expression and Molecular Characteristics

\begin{tabular}{|c|c|c|c|c|}
\hline \multirow[b]{2}{*}{ Characteristic } & \multirow[b]{2}{*}{ Total (\%) } & \multicolumn{2}{|l|}{ LGR5 } & \multirow[b]{2}{*}{$P$} \\
\hline & & $\begin{array}{l}\text { Negative } \\
(\%)\end{array}$ & $\begin{array}{l}\text { Positive } \\
(\%)\end{array}$ & \\
\hline Patients & $788(100)$ & $252(32)$ & $536(68)$ & \\
\hline \multicolumn{5}{|l|}{ CIMP } \\
\hline Negative & $377(48)$ & $115(30)$ & $262(70)$ & $0.021^{*}$ \\
\hline Low & $375(48)$ & $115(31)$ & $260(69)$ & \\
\hline High & $36(4)$ & $22(61)$ & $14(39)$ & \\
\hline \multicolumn{5}{|l|}{ MSI } \\
\hline Negative & $682(87)$ & $207(30)$ & $475(70)$ & $0.011^{*}$ \\
\hline Low & $52(6)$ & $18(35)$ & $34(65)$ & \\
\hline High & $54(7)$ & $27(50)$ & $27(50)$ & \\
\hline Patients & $749(100)$ & $238(32)$ & $511(68)$ & \\
\hline \multicolumn{5}{|l|}{ KRAS } \\
\hline Wt & $552(73)$ & $176(32)$ & $376(68)$ & $0.929^{\dagger}$ \\
\hline Mt & 197 (27) & $62(32)$ & $135(68)$ & \\
\hline Patients & 707 (100) & $221(31)$ & $486(69)$ & \\
\hline \multicolumn{5}{|l|}{$B R A F$} \\
\hline Wt & $679(96)$ & $208(30)$ & $471(70)$ & $0.095^{\dagger}$ \\
\hline Mt & $28(4)$ & $13(46)$ & $15(54)$ & \\
\hline
\end{tabular}

*Pearson $\chi^{2}$ test.

${ }^{\dagger}$ Fisher's exact test.

CIMP, CpG island methylator phenotype; MSI, microsatellite instability; Mt, mutation; Wt, wild type.

highly expressed in both colorectal adenomas and cancers. However, it remains unknown whether $L G R 5$ expression is altered during the adenoma-carcinoma transition. Samples from 24 cases of CRCs arising from preexisting adenomas were collected for comparison, and no significant difference in LGR5 expression was found between the adenoma and carcinoma portions (Figure 3A). Next, samples from 24 cases of ulcerofungating CRCs with regional lymph node metastasis were collected; for each cancer, LGR5 expression was measured in three spots: superficial fungating area, invasive fronts, and lymph node metastasis. Notably, LGR5

Table 3 Results of Multivariate Analysis for Survival Rate in Colorectal Cancers

\begin{tabular}{lllll}
\hline Variable & Subgroup & HR & $95 \%$ CI & $P^{*}$ \\
\hline Age & $\geq 60 /<60$ years & 1.569 & $1.181-2.085$ & 0.002 \\
$\begin{array}{l}\text { Site } \\
\text { Differentiation }\end{array}$ & $\begin{array}{c}\text { Distal/proximal } \\
\text { Poor/moderate/ } \\
\text { well }\end{array}$ & 0.739 & $0.549-0.995$ & 0.046 \\
& $\begin{array}{c}\text { Positive/negative } \\
\text { Lymphatic } \\
\quad \text { invasion }\end{array}$ & 1.574 & $1.172-2.116$ & 0.003 \\
$\begin{array}{l}\text { Venous } \\
\quad \text { invasion }\end{array}$ & Positive/negative & 1.456 & $1.047-2.024$ & 0.026 \\
$\begin{array}{l}\text { Stage } \\
\text { LGR5 }\end{array}$ & IV/III/II/I & 3.047 & $2.496-3.719$ & $<0.0001$ \\
\hline
\end{tabular}

*Cox proportional hazard model.

$H R$, hazard ratio. 
A
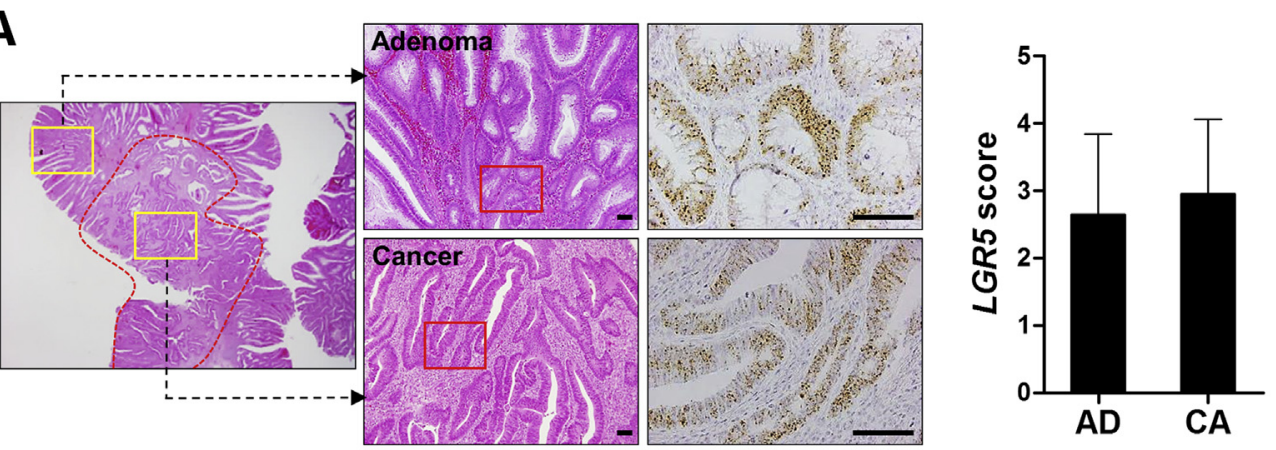

B
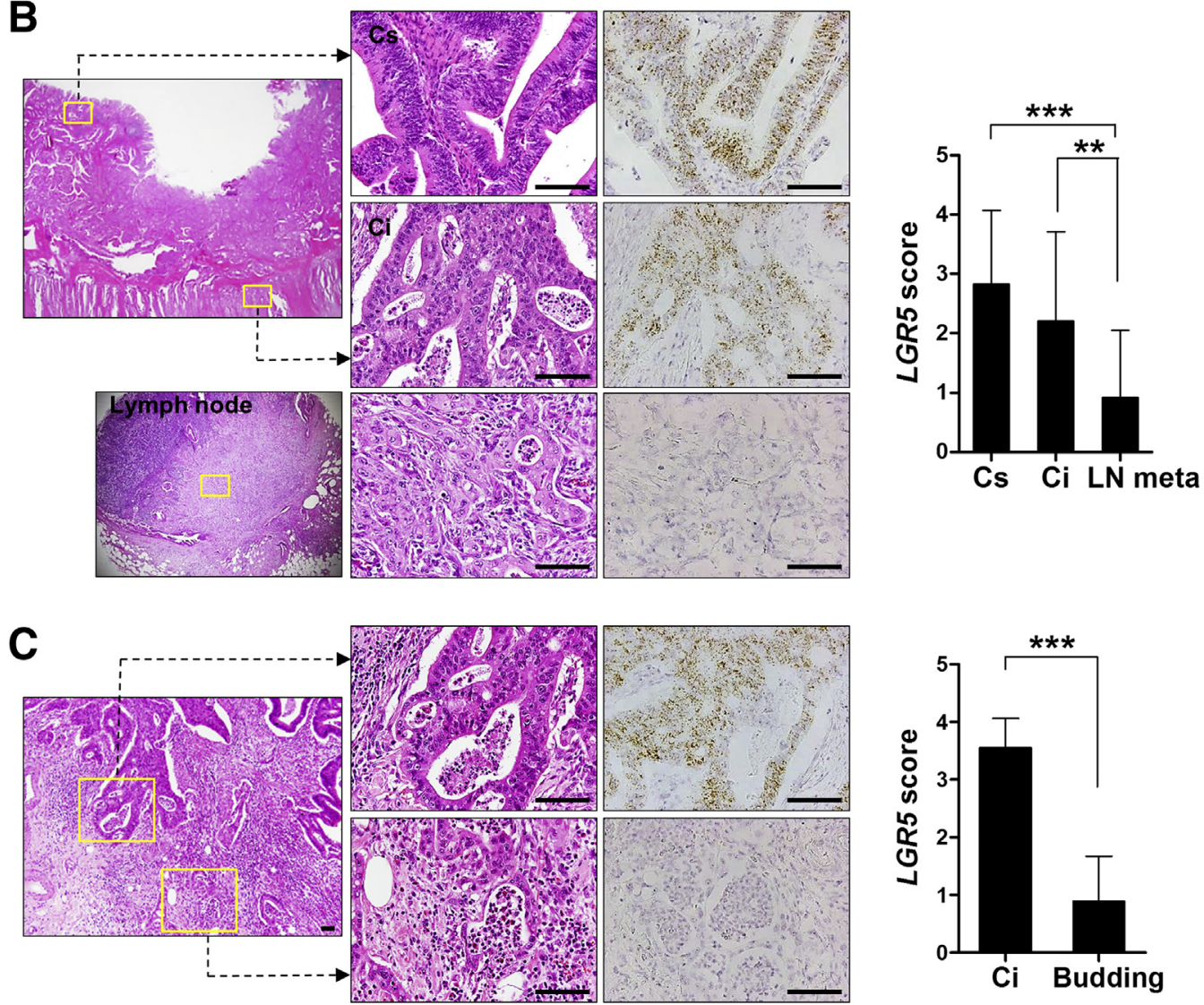

Figure 3 Declined LGR5 expression in the budding cancer cells and lymph node metastasis. RNA in situ hybridization for LGR5 was performed on the tissue microarrays containing colorectal adenomas and cancers. A: There is no significant difference in LGR5 expression between adenoma and carcinoma portions. Red dotted line depicts the boundary between adenoma and carcinoma areas. Yellow boxed areas are shown at higher magnification in the middle panels, and red boxed areas in the middle are shown at higher magnification in the right panels. B: A surface area and an invasive area was designated as Cs and Ci, respectively, in ulcerofungating cancers with lymph node metastasis. LGR5 score is much lower in metastatic cancers in the lymph nodes than in Cs and Ci cancers. Yellow boxed areas are shown at higher magnification in the middle panels. C: At the invasive fronts of colon cancers. LGR5 expression substantially declines in the budding cancer cells. Yellow boxed areas are shown at higher magnification in the middle panels. Data are expressed as means \pm SD. $n=23$ (A); $n=24$ (B); $n=36$ (C). ${ }^{* * P}<0.01,{ }^{* *} P<0.001$. Scale bars $=50 \mu \mathrm{m}$. AD, adenoma; CA, cancer; LN, lymph node.

score was significantly lower in the metastatic cancer cells and did not differ between surface and invasive areas (Figure 3B). Since cancer budding is known to be a risk factor for metastasis, it was determined whether $L G R 5$ expression is altered in the budding cells at the invasive fronts, and it was found that LGR5 scores were markedly declined in the budding cancer cells $(n=36)$ (Figure 3C).
Wnt-Signaling or Epithelial-Mesenchymal Transition Pathway Is Not Involved in LGR5 Down-Regulation in Tumor Budding

LGR5 is a target gene of Wnt signaling, and nuclear $\beta$-catenin expression is known to represent an enhanced activation of the Wnt pathway. Therefore, the correlation between LGR5 and nuclear $\beta$-catenin expression was 
examined in the budding cells to investigate whether the Wnt pathway is involved in LGR5 suppression in the budding cells. However, in all of the cases showing LGR5 down-regulation in the budding areas $(n=23)$, nuclear $\beta$-catenin expression in the budding cells remained similar to that in the nonbudding cancer cells (Figure 4A); this finding indicates that the abrupt LGR5 suppression observed in the tumor budding is not due to the decreased

A

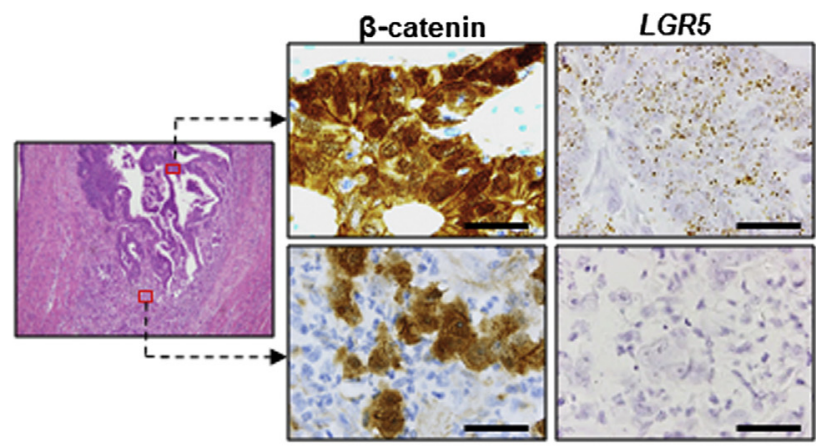

B
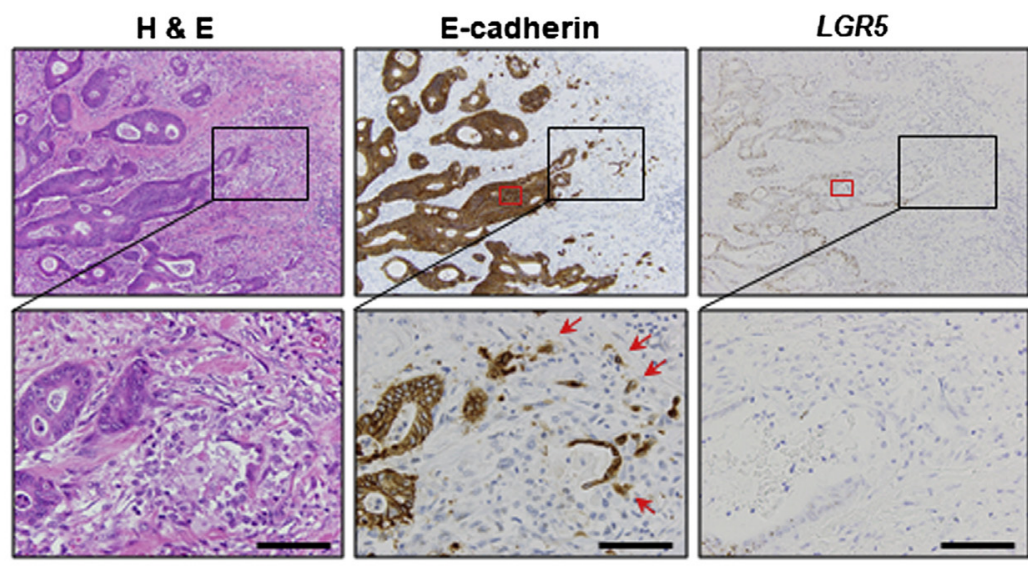

$\mathbf{E}$

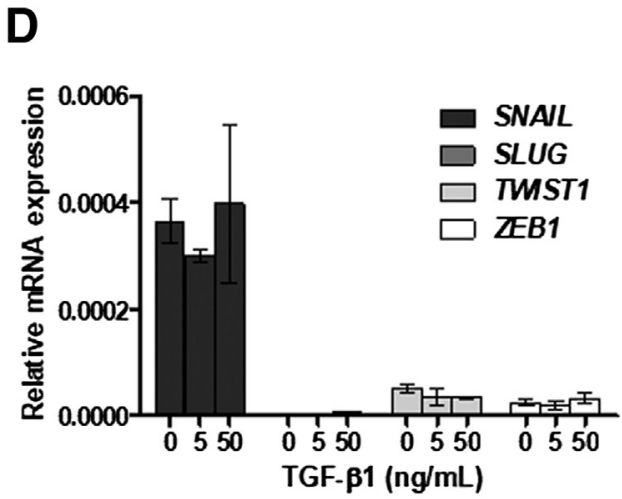

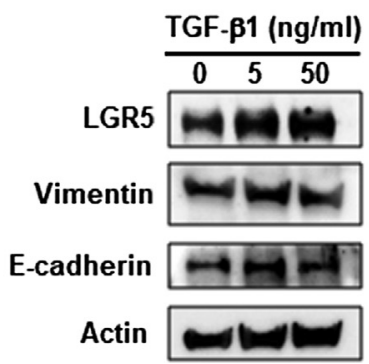

C
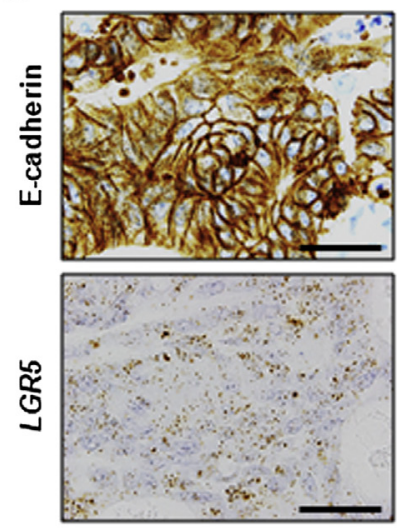

Figure 4 Wnt pathway and epithelial mesenchymal transition (EMT) are not associated with LGR5 down-regulation in the budding cancer cells. A: In the colon cancers expressing both LGR5 and nuclear $\beta$-catenin, budding cells at the invasive fronts show markedly reduced LGR5 expression while retaining nuclear $\beta$-catenin. Red boxed areas in left panel are shown at higher magnification in middle and right panels. B: Representative micrograph of budding cancer cells with abnormal E-cadherin expression patterns (loss of membranous expression or cytoplasmic expression) indicated by arrows show declined LGR5 expression. Black boxed areas in top panels are shown at higher magnification in bottom panels. C: Higher-magnification images corresponding to the red boxed regions in B. Cancer cells with strong membranous E-cadherin expression exhibit high levels of LGR5 mRNA. D: LoVo cells were treated with transforming growth factor (TGF)- $\beta_{1}(0,5$, or $50 \mathrm{ng} / \mathrm{mL})$ for 24 hours, and the levels of EMT-related transcription factors (EMT-TFs) were determined by real-time PCR. E: Upon the treatment of TGF- $\beta_{1}$ for 24 hours, immunoblot assays were performed to evaluate the LGR5 expression. F: Forty-eight hours after transfection with a control (Ctl) or EMT-TFs [zinc finger protein SNAI1 (SNAIL), zinc finger protein SNAI2 (SLUG), and ZEB1 (zinc finger E-box-binding homeobox 1)]-expressing plasmid $(5 \mu \mathrm{g})$, immunoblot assay was performed using the antibodies indicated in the figure. Data are expressed as means \pm SD (D). $n=23$ (A). Scale bars: $20 \mu \mathrm{m}$ (A and $\mathbf{C}) ; 50 \mu \mathrm{m}$ (B). 
Wnt-signaling activation. Epithelial-mesenchymal transition (EMT) might be the underlying mechanism of tumor budding at the invasive fronts in CRCs. Budding cells frequently showed abnormal E-cadherin expression patterns, that is, reduced or incomplete membranous expression, a crucial molecular feature of EMT, was accompanied by suppression of LGR5 expression (Figure 4B). On the other hand, nonbudding tumor cells with high levels of LGR5 expression showed a strong membranous E-cadherin expression (Figure 4C). Therefore, it is possible to hypothesize that EMT-signaling activation in budding cells may lead to LGR5 down-regulation. To identify the EMT-related transcription factors (EMT-TFs) in CRCs, LoVo cells were treated with TGF- $\beta_{1}$, an EMT inducer. However, no significant alterations were noted in the mRNA expression of four well-known EMT-TFs, SNAIL, SLUG, TWIST1, and ZEB1 (Figure 4D). LGR5 expression was slightly increased on TGF- $\beta_{1}$ treatment,
A
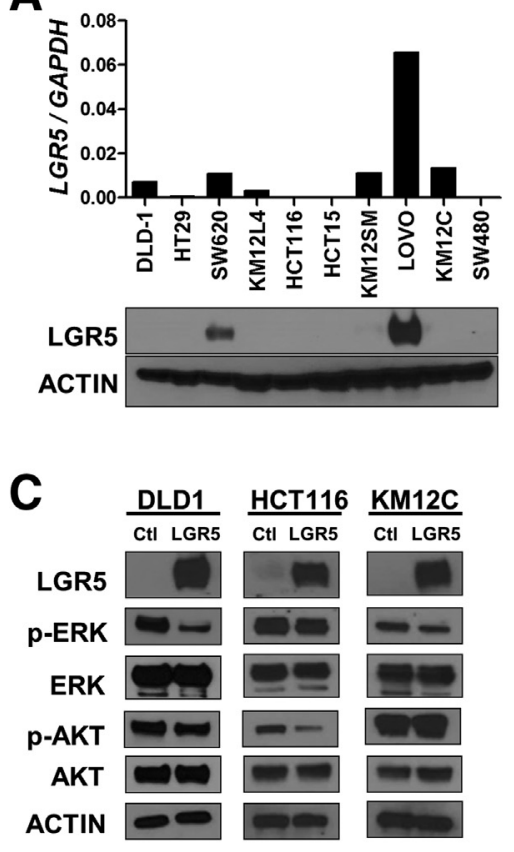

B
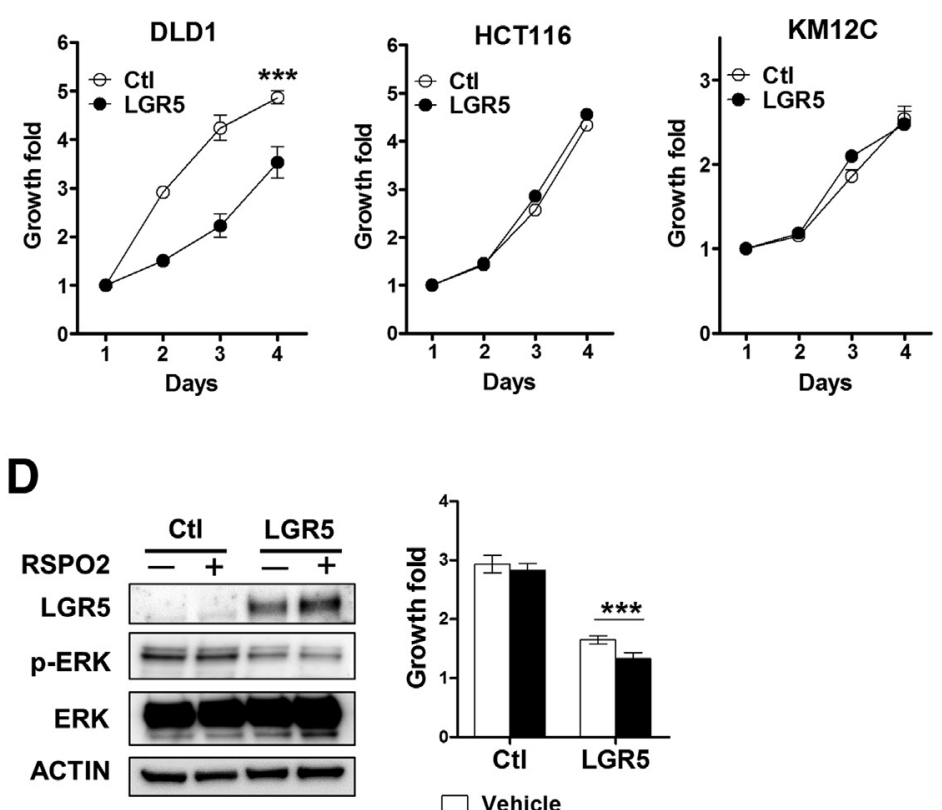

RSPO2: 100ng/mL
E

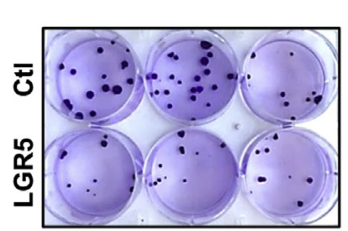

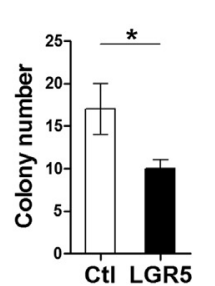

$\mathbf{F}$

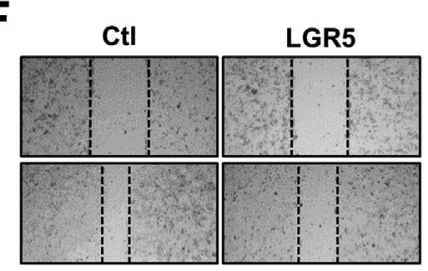

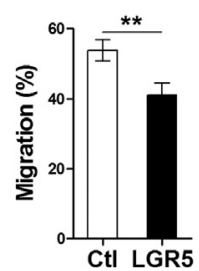

G

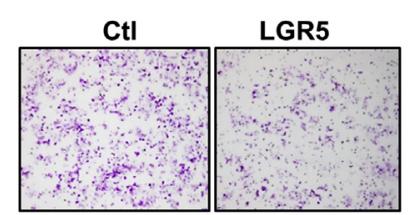

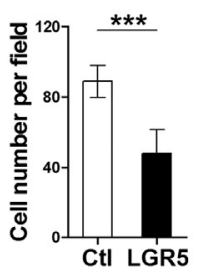

Figure 5 The inhibitory effects of LGR5 on colorectal cancer (CRC) cell growth and migration. A: The mRNA and protein levels of LGR5 in human CRC cell lines were assessed by real-time PCR and immunoblot assays. B: CRC cell lines (DLD1, HCT116, and KM12C) with low level of LGR5 expression was transfected with a control (Ctl) or a LGR5-expressing plasmid. Cell growth was determined by Cell Counting Kit-8 (Dojindo, Kumamoto, Japan) at the indicated times. C: Twenty-four hours after transfection with a Ctl or a LGR5-expressing plasmid, immunoblot assay was performed using the antibodies indicated in the figure. D: DLD1 cells transfected with a Ctl or a LGR5-expressing plasmid were treated with $100 \mathrm{ng} / \mathrm{mL}$ R-spondin (RSP0)-2 for 2 hours, immunoblot assay was performed and cell growth was measured 3 days after RSP02 treatment. E: Colony formation assay was performed by counting the number of colonies from Ctl or LGR5-expressing DLD1 cells. F and G: The effect of LGR5 expression on migration activity of DLD1 cells was evaluated by wound healing and transwell migration assays. Cellular migration was photographed at 0 and 48 hours. Dashed lines indicate the approximate edge of the wound. Data are expressed as means \pm SD $(\mathbf{D}-\mathbf{G}) .{ }^{*} P<0.05,{ }^{* *} P<0.01,{ }^{* * *} P<0.001$. 
whereas there were no changes in the expression levels of EMT-related proteins, such as vimentin and E-cadherin (Figure 4E). Since TGF- $\beta_{1}$ failed to induce the expression of EMT-related proteins in colon cancer cells, EMT-TFs including SNAIL, SLUG, and ZEB1 were directly overexpressed. SNAIL and SLUG overexpression resulted in reduced claudin-1 expression, whereas vimentin was only slightly increased by SNAIL overexpression, and E-cadherin expression was not changed by any EMT-TFs (Figure 4F), indicating a partial induction of EMT program. A decrease in the expression of LGR5 was not observed with overexpression of EMT-TFs (Figure 4F). Additionally, RNA ISH was performed for SNAIL, SLUG, and ZEBI to examine whether EMT-TFs are expressed in budding cells in CRCs (Supplemental Table S3). However, none of them were detected in the tumor-budding nests in any CRCs but one, whereas some stromal cells surrounding cancer cells were found to express EMT-TFs (Supplemental Figure $\mathrm{S} 1$ ). These findings suggest that $L G R 5$ suppression in the tumor budding of CRCs is not associated with altered Wnt signaling or EMT pathway driven by known EMT-TFs.

\section{Effects of LGR5 Expression on the Growth and Migration of CRC Cells}

To explore the functional roles of LGR5 in CRCs, 10 CRC cell lines were screened and LGR5 protein levels were found to be low in 8 of the 10 cell lines (Figure 5A). LGR5 was overexpressed in 3 cell lines-DLD1, HCT116, and $\mathrm{KM} 12 \mathrm{C}$ - and a relatively attenuated proliferation was observed in DLD1 cells transfected with LGR5 compared with those transfected with a control plasmid; conversely, there was no difference in growth in HCT116 or KM12C cells (Figure 5B). As cancer cell survival often involves AKT- and mitogen-activated protein kinase-signaling pathways, the activation of AKT and ERK proteins was examined. pERK level was decreased in DLD1 cells when LGR5 overexpression was induced; however, pAKT was not changed (Figure 5C), suggesting a possibility of mitogen-activated protein kinase pathway involvement in LGR5-induced growth restriction in DLD1 cells. To confirm the functional LGR5 protein expression on the cell surface, DLD1 cells were treated with RSPO2, previously reported to suppress CRC growth by binding to LGR5. ${ }^{34}$ As expected, LGR5-transfected DLD1 cancer cells showed a further decreased growth rate on RSPO2 treatment (Figure 5D). However, ERK activation was not altered by RSPO2, implying a complicated LGR5-RSPO2-mediated signal crosstalk for CRC growth. In addition, LGR5 overexpression resulted in a lower colony-formation ability in LGR5-transfected DLD1 cells (Figure 5E), and woundhealing (Figure 5F) and migration assays (Figure 5G) also demonstrated a decreased migratory capacity of DLD1 cells when transfected with LGR5. To further confirm the LGR5 effects on cancer cell growth and migration, LGR5 was knocked down in LoVo cells by transfecting LGR5 siRNA pool. Reduced LGR5 expression did not have any influence on the growth of cancer cells (Figure 6, A and B), but colony-formation capacity was significantly improved (Figure 6C). Enhanced migratory activity was demonstrated in the transwell migration assay but not in the woundhealing assay (Figure 6, D and E). Taken together, LGR5 has suppressive roles in the proliferation and migration activities of CRCs, although the functional effects are limited and may vary between individual cancer cases.

\section{Discussion}

In this study, RNA ISH was applied to assess the expression of $L G R 5$ transcripts in a large-scale cohort of human CRCs, and LGR5 was found to be an independent prognostic marker associated with better survival. This result is contrary to those from most previous studies reporting worse prognostic influence of LGR5 in CRCs,${ }^{20-24}$ wherein LGR5 expression was evaluated by immunohistochemistry analysis detecting LGR5 protein. Therefore, the discrepancy may be explained by the difference in methods, but we believe that our findings on the prognostic value of LGR5 in human CRCs is more reliable considering the lack of trustworthy anti-LGR5 antibodies for immunohistochemistry analysis. Moreover, most recent studies have shown a tumor-suppressive role of LGR5 signaling in human CRCs. ${ }^{34,35}$ As RNA ISH is of only limited use for a practical purpose, the development of antibodies against LGR5 for immunohistochemistry analysis is required to confirm our findings and to reexamine the prognostic importance of LGR5 protein.

CRCs develop from distinct molecular pathways: chromosomal instability, MSI, and CIMP pathways. ${ }^{36} L G R 5$ is highly expressed in human CRC precancerous lesions, and in particular, tubular adenomas express a higher level of $L G R 5$ than do traditional and sessile serrated adenomas, ${ }^{28}$ suggesting that a large proportion of human CRCs develop from $L_{G R 5^{+}}$cells more likely through the chromosomal-instability pathway than the MSI or CIMP pathways. To support of this notion, it was found that $L G R 5$ positivity was positively correlated with chromosomalinstability pathway-associated histopathologic characteristics, which include left-sided location, nuclear $\beta$-catenin expression representing an abnormal Wnt signal activation (Table 1), and negative correlations with MSI, CIMP-high, and BRAF mutation (Table 2). Considering that besides LGR5, several additional intestinal stem cell markers have been identified, such as BMII, LRIGI, HOPX, and TERT, it would be interesting to investigate which intestinal stem cell markers are more related to MSI and CIMP pathways in CRC carcinogenesis.

LGR5 is considered one of the most promising CSC markers of CRCs. It has been demonstrated that $\mathrm{LGR}^{+}$ cancer cells functionally act as stem cells in human CRCs. ${ }^{17,37,38}$ Not only LGR5 but also several surface 


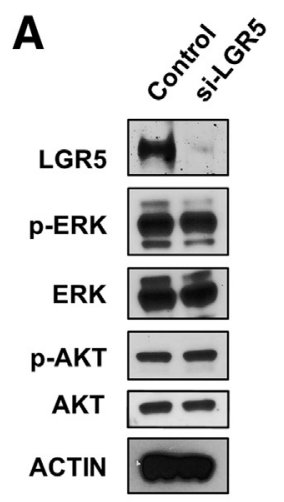

B

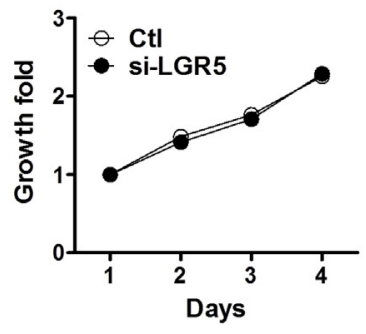

C

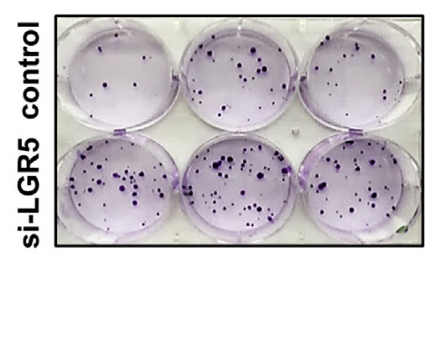

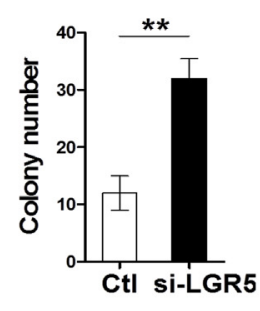

D

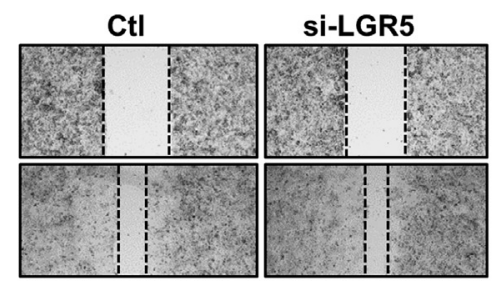

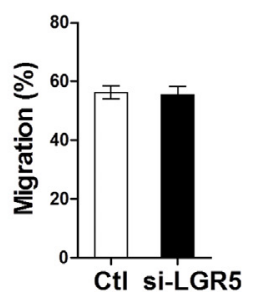

$\mathbf{E}$
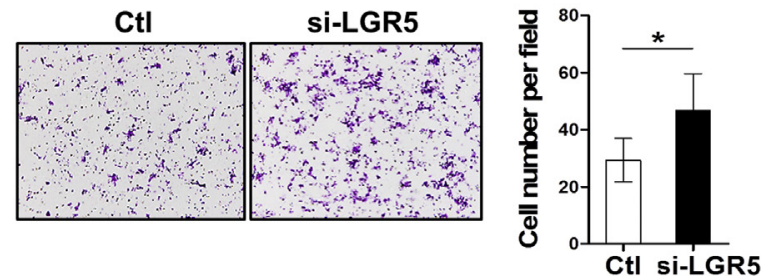

Figure 6 Effects of LGR5 silencing on the growth and migration of colorectal cancer cells. A: LGR5 was down-regulated by transfection of LGR5 siRNA (si-LGR5) pool into LoVo cells. Immunoblot analysis was performed using the antibodies indicated in the figure. B and C: Cell growth and colony formation assays were performed after transfection of control (Ctl) or si-LGR5 pool. D and E: The effect of LGR5 silencing on the migration of LoVo cells was evaluated by Wound healing and transwell migration assays. Cellular migration was photographed at 0 and 48 hours. Dashed lines indicate the approximate edge of the wound. Data are expressed as means $\pm \mathrm{SD}(\mathbf{C}-\mathbf{E}) .{ }^{*} P<0.05,{ }^{*}{ }^{*} P<0.01$.

markers have been proposed as CSC markers, such as CD133, CD44, CD24, and CD166. ${ }^{39-41}$ We therefore investigated whether there is any association between LGR5 and these candidate CSC markers. However, on the analysis in fresh-frozen human CRC tissues, no correlation was observed, indicating that $L G R 5^{+}$cells are less likely to be overlapped with other candidate CSC populations. Using $L G R 5^{+}$stem cells in the normal intestinal crypts, additional stem cell-related markers, such as ASCL2, EPHB2, and OLFM4, have been identified, and they are called stem cell signature genes. ${ }^{42}$ ASCL2 has been shown to activate a gene signature fundamental to the intestinal stem cell state, ${ }^{43}$ and OLFM4 was suggested to be a highly specific and robust LGR5 stem cell marker. ${ }^{44}$ These stem cell-related markers tend to be coexpressed in the colorectal precancerous lesions. ${ }^{28}$ However, no significant association was observed between LGR5 and other stem cell signature genes in primary CRC samples. These results suggest that stem cell hierarchy in the normal crypts is maintained in the early stage of colon tumorigenesis, but is disrupted and lost as colon cancers develop and progress.

Herein it was found that a high level of LGR5 expression was persistent during adenoma-to-carcinoma transition. Also, LGR5 expression was unchanged even when cancer cells invaded into deeper layers. Remarkably, LGR5 expression was dramatically reduced in the budding cells at the invasive fronts, which probably contributes to the low levels of LGR5 in the metastatic cancer cells in the lymph nodes. Since $L G R 5$ is one of the target genes of the Wnt pathway, it was examined whether LGR5 down-regulation in the budding cells is due to declined Wnt-signaling activity. However, nuclear $\beta$-catenin expression was observed in the budding cancer cells to be at the same level as in the nonbudding cells, indicating that LGR5 suppression occurs despite the presence of enhanced Wntsignaling activation.

The budding area is considered as the focus in which cancer cells undergo dramatic morphologic changes to facilitate invasion through EMT. ${ }^{45}$ Therefore, the influence of EMT activation was evaluated on LGR5 expression in CRC cells. However, neither TGF- $\beta_{1}$ treatment nor EMTTF overexpression reduced the LGR5 expression in LoVo cells; conversely, TGF- $\beta_{1}$ marginally increased LGR5 expression, which is consistent with a recent report demonstrating a positive correlation between LGR5 expression and TGF- $\beta$ signaling. ${ }^{35}$ Although tumor budding is closely related to EMT, whether in CRCs EMT-TFs are involved in the down-regulation of E-cadherin in budding cells is controversial. For example, Bronsert et $\mathrm{al}^{46}$ and Galván et $\mathrm{al}^{47}$ have shown the expression of EMT-TFs in tumor-budding nests as well as stromal cells. However, most recently, Yamada et $\mathrm{al}^{48}$ demonstrated by immunohistochemistry that EMT-TFs are not observed in budding tumor cells with reduced E-cadherin expression. EMT-TFs were found by RNA ISH to be expressed only in surrounding stromal cells but not in budding cancer cells. 
In addition, although budding cells often showed abnormal E-cadherin expression, the majority of them still retained epithelial morphology, and vimentin expression was not detected in all of the cases in this study (Supplemental Figure S1), indicating that tumor budding may represent an EMT-like process but not a full EMT phenotype in CRCs. Taken together, these findings suggest that LGR5 suppression in the budding CRC cells is less likely to be associated with the Wnt pathway or EMT driven by known EMT-TFs. Further studies are required to unravel the underlying molecular mechanism by which LGR5 expression is suppressed in the budding cancer cells at the invasive fronts.

This study demonstrates that induced LGR5 overexpression leads to attenuation in the growth, colony formation, and migration activities, supporting the previous findings of LGR5 as a tumor suppressor in CRCs. ${ }^{34,35,49}$ In DLD1 cells, LGR5 expression resulted in a reduction in the pERK level, whereas the pAKT level was unchanged, suggesting that LGR5 exerts its suppressive effect by influencing the mitogen-activated protein kinase pathway. However, this finding was observed only in DLD1 cells. HCT116 and KM12C cells showed no difference in growth rates on LGR5 transfection, and LGR5 silencing in LoVo cells had no influence on proliferation, while increasing colony-forming ability instead. In addition, ERK activation was not altered when LGR5-transfected DLD1 cell growth was further suppressed by RSPO2 treatment, thus indicating a complicated crosstalk between RSPO and LGR5 signaling. These results suggest that the functional impact of LGR5 on the growth of CRCs and the involved signaling pathways vary depending on the cellular context. To further complicate the issue, LGR5 expression has been reported to have oncogenic function in other cancers. For example, it has been reported that LGR5 plays a key role in Wnt and mitogen-activated protein kinase kinase (MEK)/ERKsignaling pathways to enhance proliferation and survival in neuroblastomas. ${ }^{16}$ In glioblastoma cells, silencing of LGR5 induces apoptosis ${ }^{50}$ and LGR5 acts as a growth- and invasion-promoting factor in breast cancer cells. ${ }^{51}$ These findings indicate that, depending on the cancer type, LGR5 can function as either a tumor suppressor or an oncogene.

Recently, it was demonstrated that $L G R 5^{+}$CRC cells reappear from the $L G R 5^{-}$cell population after removal of $L G R 5^{+}$cells in a tumor mass, showing a remarkable plasticity of CSCs. ${ }^{18,19}$ These results led us to speculate that this finding of abrupt appearance of $L G R 5^{-}$cells out of $L G R 5^{+}$ cancer cells in the budding foci may provide additional evidence of the plasticity of $L G R 5^{+}$cells in CRCs. Given that tumor budding is considered an early event in the metastatic process, the transition from $L G R 5^{+}$to $L G R 5^{-}$ cells may occur to confer on cancer cells the ability to detach and invade deeper layers. However, it is also possible that $L G R 5$ has no functional implications in the budding or invasion processes and may be a part of a bystander phenomenon resulting from substantial changes in the signaling pathways of the budding cells. Further studies are needed to address this possibility.

To summarize, this study shows that LGR5 is an independent prognostic marker for better clinical outcomes in CRCs. Enhanced LGR5 expression remains persistent during adenoma-carcinoma transition, but markedly declines in the budding cancer cells at the invasive fronts, which is not associated with the Wnt- or EMT-signaling pathway. LGR5 overexpression attenuates proliferation, migration, and colony-forming capacities in colon cancer cells. These findings indicate that LGR5 functions as a tumor suppressor in the late stages of CRC progression.

\section{Acknowledgments}

We thank Hyun Ju Park, Seung Hee Jung, and Hye Jung Lee (SuperBioChips Laboratories, Seoul, Republic of Korea) for excellent technical support.

\section{Supplemental Data}

Supplemental material for this article can be found at https://doi.org/10.1016/j.ajpath.2018.06.012.

\section{References}

1. Barker N, Van Es JH, Kuipers J, Kujala P, Van Den Born M Cozijnsen M, Haegebarth A, Korving J, Begthel H, Peters PJ: Identification of stem cells in small intestine and colon by marker gene Lgr5. Nature 2007, 449:1003-1007

2. Glinka A, Dolde C, Kirsch N, Huang YL, Kazanskaya O, Ingelfinger D, Boutros M, Cruciat CM, Niehrs C: LGR4 and LGR5 are $\mathrm{R}$-spondin receptors mediating $\mathrm{Wnt} / \mathrm{\beta}$-catenin and $\mathrm{Wnt} / \mathrm{PCP}$ signalling. EMBO Rep 2011, 12:1055-1061

3. de Lau W, Barker N, Low TY, Koo B-K, Li VS, Teunissen H, Kujala P, Haegebarth A, Peters PJ, van de Wetering M: Lgr5 homologues associate with Wnt receptors and mediate R-spondin signalling. Nature 2011, 476:293-297

4. Jaks V, Barker N, Kasper M, Van Es JH, Snippert HJ, Clevers H, Toftgård R: Lgr5 marks cycling, yet long-lived, hair follicle stem cells. Nat Genet 2008, 40:1291-1299

5. Huch M, Dorrell C, Boj SF, Van Es JH, van de Wetering M, Li VS, Hamer K, Sasaki N, Finegold MJ, Haft A: In vitro expansion of single Lgr5+ liver stem cells induced by Wnt-driven regeneration. Nature 2013, 494:247-250

6. Ng A, Tan S, Singh G, Rizk P, Swathi Y, Tan TZ, Huang RY-J, Leushacke M, Barker N: Lgr5 marks stem/progenitor cells in ovary and tubal epithelia. Nat Cell Biol 2014, 16:745-757

7. Barker N, Ridgway RA, Van Es JH, Van De Wetering M, Begthel H, Van Den Born M, Danenberg E, Clarke AR, Sansom OJ, Clevers H: Crypt stem cells as the cells-of-origin of intestinal cancer. Nature 2009, 457:608-611

8. Schepers AG, Snippert HJ, Stange DE, van den Born M, van Es JH, van de Wetering M, Clevers H: Lineage tracing reveals Lgr5+ stem cell activity in mouse intestinal adenomas. Science 2012, 337: 730-735

9. Becker L, Huang Q, Mashimo H: Immunostaining of Lgr5, an intestinal stem cell marker, in normal and premalignant human gastrointestinal tissue. ScientificWorldJournal 2008, 8:1168-1176

10. Fan X-S, Wu H-Y, Yu H-P, Zhou Q, Zhang Y-F, Huang Q: Expression of Lgr5 in human colorectal carcinogenesis and its 
potential correlation with $\beta$-catenin. Int J Colorectal Dis 2010, 25 $583-590$

11. Uchida H, Yamazaki K, Fukuma M, Yamada T, Hayashida T, Hasegawa H, Kitajima M, Kitagawa Y, Sakamoto M: Overexpression of leucine-rich repeat-containing $\mathrm{G}$ protein-coupled receptor 5 in colorectal cancer. Cancer Sci 2010, 101:1731-1737

12. Al-Kharusi MR, Smartt HJ, Greenhough A, Collard TJ, Emery ED, Williams AC, Paraskeva C: LGR5 promotes survival in human colorectal adenoma cells and is upregulated by PGE 2: implications for targeting adenoma stem cells with NSAIDs. Carcinogenesis 2013, 34:1150-1157

13. Baker A-M, Graham TA, Elia G, Wright NA, Rodriguez-Justo M: Characterization of LGR5 stem cells in colorectal adenomas and carcinomas. Sci Rep 2015, 5:8654

14. Yamamoto Y, Sakamoto M, Fujii G, Tsuiji H, Kenetaka K, Asaka M, Hirohashi S: Overexpression of orphan G-protein-coupled receptor, Gpr49, in human hepatocellular carcinomas with $\beta$-catenin mutations. Hepatology 2003, 37:528-533

15. Tanese $\mathrm{K}$, Fukuma M, Yamada $\mathrm{T}$, Mori $\mathrm{T}$, Yoshikawa $\mathrm{T}$, Watanabe W, Ishiko A, Amagai M, Nishikawa T, Sakamoto M: G-protein-coupled receptor GPR49 is up-regulated in basal cell carcinoma and promotes cell proliferation and tumor formation. Am J Pathol 2008, 173:835-843

16. Vieira GC, Chockalingam S, Melegh Z, Greenhough A, Malik S, Szemes M, Park JH, Kaidi A, Zhou L, Catchpoole D: LGR5 regulates pro-survival MEK/ERK and proliferative Wnt/ $\beta$-catenin signalling in neuroblastoma. Oncotarget 2015, 6:40053

17. Kemper K, Prasetyanti PR, De Lau W, Rodermond H, Clevers H, Medema JP: Monoclonal antibodies against Lgr5 identify human colorectal cancer stem cells. Stem Cells 2012, 30: $2378-2386$

18. Shimokawa M, Ohta Y, Nishikori S, Matano M, Takano A, Fujii M, Date S, Sugimoto S, Kanai T, Sato T: Visualization and targeting of LGR5+ human colon cancer stem cells. Nature 2017, 545: 187-192

19. de Sousa e Melo F, Kurtova AV, Harnoss JM, Kljavin N, Hoeck JD, Hung J, Anderson JE, Storm EE, Modrusan Z, Koeppen H: A distinct role for Lgr5 + stem cells in primary and metastatic colon cancer. Nature 2017, 543:676-680

20. He S, Zhou H, Zhu X, Hu S, Fei M, Wan D, Gu W, Yang X, Shi D, Zhou J: Expression of Lgr5, a marker of intestinal stem cells, in colorectal cancer and its clinicopathological significance. Biomed Pharmacother 2014, 68:507-513

21. Takahashi H, Ishii H, Nishida N, Takemasa I, Mizushima T, Ikeda M, Yokobori T, Mimori K, Yamamoto H, Sekimoto M: Significance of Lgr5(+ve) cancer stem cells in the colon and rectum. Ann Surg Oncol 2011, 18:1166-1174

22. Wu X-S, Xi H-Q, Chen L: Lgr5 is a potential marker of colorectal carcinoma stem cells that correlates with patient survival. World J Surg Oncol 2012, 10:244

23. Hsu H-C, Liu Y-S, Tseng K-C, Hsu C-L, Liang Y, Yang T-S, Chen JS, Tang R-P, Chen S-J, Chen H-C: Overexpression of Lgr5 correlates with resistance to 5-FU-based chemotherapy in colorectal cancer. Int J Colorectal Dis 2013, 28:1535-1546

24. Saigusa S, Inoue $\mathrm{Y}$, Tanaka $\mathrm{K}$, Toiyama $\mathrm{Y}$, Kawamura M, Okugawa Y, Okigami M, Hiro J, Uchida K, Mohri Y: Significant correlation between LKB1 and LGR5 gene expression and the association with poor recurrence-free survival in rectal cancer after preoperative chemoradiotherapy. J Cancer Res Clin Oncol 2013, 139: $131-138$

25. Chen Q, Zhang X, Li W-M, Ji Y-Q, Cao H-Z, Zheng P: Prognostic value of LGR5 in colorectal cancer: a meta-analysis. PLoS One 2014, 9:e107013

26. Han Y, Xue X, Jiang M, Guo X, Li P, Liu F, Yuan B, Shen Y, Guo X, Zhi Q: LGR5, a relevant marker of cancer stem cells, indicates a poor prognosis in colorectal cancer patients: a meta-analysis. Clin Res Hepatol Gastroenterol 2015, 39:267-273
27. Jiang Y, Li W, He X, Zhang H, Jiang F, Chen Z: Lgr5 expression is a valuable prognostic factor for colorectal cancer: evidence from a meta-analysis. BMC Cancer 2016, 16:12

28. Jang BG, Kim HS, Kim KJ, Rhee YY, Kim WH, Kang GH: Distribution of intestinal stem cell markers in colorectal precancerous lesions. Histopathology 2016, 68:567-577

29. Ziskin JL, Dunlap D, Yaylaoglu M, Fodor IK, Forrest WF, Patel R, Ge N, Hutchins GG, Pine JK, Quirke P: In situ validation of an intestinal stem cell signature in colorectal cancer. Gut 2012, 62 $1012-1023$

30. Sobin LH, Compton CC: TNM seventh edition: what's new, what's changed: communication from the International Union Against Cancer and the American Joint Committee on Cancer. Cancer 2010, 116:5336-5339

31. Bosman FT, Carneiro F, Hruban RH, Theise ND: WHO classification of tumours of the digestive system. Geneva, Switzerland: World Health Organization, 2010

32. Boland CR, Thibodeau SN, Hamilton SR, Sidransky D, Eshleman JR, Burt RW, Meltzer SJ, Rodriguez-Bigas MA, Fodde R, Ranzani GN, Srivastava S: A National Cancer Institute Workshop on Microsatellite Instability for cancer detection and familial predisposition: development of international criteria for the determination of microsatellite instability in colorectal cancer. Cancer Res 1998, 58:5248-5257

33. Kim JH, Kim K-J, Rhee Y-Y, Oh S, Cho N-Y, Lee HS, Kang GH: Expression status of wild-type HSP110 correlates with HSP110 T17 deletion size and patient prognosis in microsatellite-unstable colorectal cancer. Mod Pathol 2014, 27:443-453

34. Wu C, Qiu S, Lu L, Zou J, Li W-f, Wang O, Zhao H, Wang H, Tang J, Chen L: RSPO2-LGR5 signaling has tumour-suppressive activity in colorectal cancer. Nat Commun 2014, 5:3149

35. Zhou X, Geng L, Wang D, Yi H, Talmon G, Wang J: R-Spondin1/LGR5 activates TGF $\beta$ signaling and suppresses colon cancer metastasis. Cancer Res 2017, 77:6589-6602

36. Jass J: Classification of colorectal cancer based on correlation of clinical, morphological and molecular features. Histopathology 2007 , 50:113-130

37. Merlos-Suárez A, Barriga FM, Jung P, Iglesias M, Céspedes MV, Rossell D, Sevillano M, Hernando-Momblona X, da Silva-Diz V, Muñoz P: The intestinal stem cell signature identifies colorectal cancer stem cells and predicts disease relapse. Cell Stem Cell 2011, 8:511-524

38. Hirsch D, Barker N, McNeil N, Hu Y, Camps J, McKinnon K, Clevers H, Ried T, Gaiser T: LGR5 positivity defines stem-like cells in colorectal cancer. Carcinogenesis 2013, 35:849-858

39. O'brien CA, Pollett A, Gallinger S, Dick JE: A human colon cancer cell capable of initiating tumour growth in immunodeficient mice. Nature 2007, 445:106-110

40. Du L, Wang H, He L, Zhang J, Ni B, Wang X, Jin H, Cahuzac N, Mehrpour M, Lu Y: CD44 is of functional importance for colorectal cancer stem cells. Clin Cancer Res 2008, 14:6751-6760

41. Yeung TM, Gandhi SC, Wilding JL, Muschel R, Bodmer WF: Cancer stem cells from colorectal cancer-derived cell lines. Proc Natl Acad Sci U S A 2010, 107:3722-3727

42. Muñoz J, Stange DE, Schepers AG, Van De Wetering M, Koo BK, Itzkovitz S, Volckmann R, Kung KS, Koster J, Radulescu S: The Lgr5 intestinal stem cell signature: robust expression of proposed quiescent '+ 4'cell markers. EMBO J 2012, 31:3079-3091

43. Schuijers J, Junker JP, Mokry M, Hatzis P, Koo B-K, Sasselli V, Van Der Flier LG, Cuppen E, van Oudenaarden A, Clevers H: Ascl2 acts as an R-spondin/Wnt-responsive switch to control stemness in intestinal crypts. Cell Stem Cell 2015, 16:158-170

44. Van der Flier LG, Haegebarth A, Stange DE, Van de Wetering M, Clevers H: OLFM4 is a robust marker for stem cells in human intestine and marks a subset of colorectal cancer cells. Gastroenterology 2009, 137:15-17

45. Zlobec I, Lugli A: Epithelial mesenchymal transition and tumor budding in aggressive colorectal cancer: tumor budding as oncotarget. Oncotarget 2010, 1:651 
46. Bronsert P, Enderle-Ammour K, Bader M, Timme S, Kuehs M, Csanadi A, Kayser G, Kohler I, Bausch D, Hoeppner J: Cancer cell invasion and EMT marker expression: a three-dimensional study of the human cancer-host interface. J Pathol 2014, 234: 410-422

47. Galván JA, Zlobec I, Wartenberg M, Lugli A, Gloor B, Perren A, Karamitopoulou E: Expression of E-cadherin repressors SNAIL, ZEB1 and ZEB2 by tumour and stromal cells influences tumourbudding phenotype and suggests heterogeneity of stromal cells in pancreatic cancer. Br J Cancer 2015, 112:1944-1950

48. Yamada N, Sugai T, Eizuka M, Tsuchida K, Sugimoto R, Mue Y, Suzuki M, Osakabe M, Uesugi N, Ishida K: Tumor budding at the invasive front of colorectal cancer may not be associated with the epithelial-mesenchymal transition. Hum Pathol 2017, 60:151-159

49. Walker F, Zhang H-H, Odorizzi A, Burgess AW: LGR5 is a negative regulator of tumourigenicity, antagonizes Wnt signalling and regulates cell adhesion in colorectal cancer cell lines. PLoS One 2011, 6:e22733

50. Nakata S, Campos B, Bageritz J, Lorenzo Bermejo J, Becker N Engel F, Acker T, Momma S, Herold-Mende C, Lichter P: LGR5 is a marker of poor prognosis in glioblastoma and is required for survival of brain cancer stem-like cells. Brain Pathol 2013, 23:60-72

51. Yang L, Tang H, Kong Y, Xie X, Chen J, Song C, Liu X, Ye F, Li N, Wang N: LGR5 promotes breast cancer progression and maintains stem-like cells through activation of $\mathrm{Wnt} / \beta$-catenin signaling. Stem Cells 2015, 33:2913-2924 